Running Head: INTOXICATED WITNESSES AND SUSPECTS: AN ARCHIVAL ANALYSIS OF THEIR INVOLVEMENT IN CRIMINAL CASE PROCESSING

Intoxicated witnesses and suspects:

An archival analysis of their involvement in criminal case processing

Francesca Palmer, Heather D. Flowe, Melanie K. Takarangi, and Joyce E. Humphries 


\begin{abstract}
Research about intoxicated witnesses and criminal suspects is surprisingly limited, considering the police believe that they are quite ubiquitous. In the present study, we assessed the involvement of intoxicated witnesses and suspects in the investigation of rape, robbery and assault crimes by analyzing cases that were referred by the police to a prosecutor's office. Results indicated that intoxicated witnesses and suspects played an appreciable role in criminal investigations: Intoxicated witnesses were just as likely as sober ones to provide a description of the culprit and to take an identification test, suggesting criminal investigators treat intoxicated and sober witnesses similarly. Moreover, intoxicated suspects typically admitted to the police that they had consumed alcohol and/or drugs, and they were usually arrested on the same day as the crime. This archival analysis highlights the many ways in which alcohol impacts testimony during criminal investigations, and underscores the need for additional research to investigate best practices for obtaining testimony from intoxicated witnesses and suspects.
\end{abstract}

Keywords: Deception and Confessions, Eyewitness Memory, Procedural Justice, Public Policy and Law 


\section{Intoxicated Witnesses and Suspects: An Archival Analysis of their Involvement in}

\section{Criminal Case Processing}

Serious crimes often involve perpetrators and victims who are under the influence of drugs (Roizen, 1993; Testa, 2002). What is more, bystanders can also be intoxicated. Indeed, the results of a recent study of police officers suggests that people who witness crime may often be under the influence of alcohol: Evans et al. (2009) found that $75 \%$ of US police officers believed that they commonly encounter intoxicated witnesses whilst working on cases. In addition, officers reported that most of these witnesses are moderately intoxicated, most are using alcohol only, and most are likely to be over the legal limit. Other research similarly suggests that perpetrators and victims may often be under the influence during rape, robbery and assault crimes (Roizen, 1993; Testa, 2002). Taken together, this research indicates that intoxicated witnesses are prevalent.

A large body of research demonstrates that alcohol can have a detrimental effect on memory (e.g., Bisby, Leitz, Morgan, \& Curran, 2010; Brown, Brignell, Dhiman, Curran, \& Kamboj, 2010; Clifasefi, Takarangi, \& Bergman, 2006; Maylor \& Rabbitt, 1993; Ray \& Bates, 2006; Soraci et al., 2007). For example, in general, alcohol has a negative impact on memory for personally experienced events (Hashtroudi, Parker, DeLisi, Wyatt, \& Mutter, 1984). Studies from the witness memory literature show that alcohol intoxication has an impact on the accuracy of testimony (Read, Yuille, \& Tollestrup, 1992; Schreiber Compo et al., 2011; van Oorsouw \& Merckelbach, 2012; Yuille \& Tollestrup, 1990) and witness identifications (Dysart, Lindsay, MacDonald, \& Wicke, 2002; Read et al., 1992; Valentine, Fausia, Fantham \& Davis, 2012; Yuille \& Tollestrup, 1990). 
Given the potential for alcohol to negatively impact memory, it might seem that the police should interview only sober witnesses. However, in fact, alcohol's effects on memory are varied, depending on a host of factors. For example, we know that the salience of the to-be-remembered information is important. Alcohol appears to maintain attention on central or salient cues in the environment at the expense of attention to peripheral cues, a phenomenon known as alcohol myopia (Read et al., 1992; Schreiber Compo et al., 2011; Steele \& Joseph, 1990; van Oorsouw \& Merckelbach, 2012). Hence, intoxicated witnesses may provide accurate information about some aspects of the crime. Additionally, in crimes such as rape, a victim who was under the influence is often the only witness to the crime who can provide information regarding the criminal perpetrator (Flowe, Mehta, \& Ebbesen, 2011). This being the case, the police cannot altogether avoid interviewing intoxicated witnesses. Thus, it is important to learn more about the role that intoxicated witnesses and suspects play in criminal case investigations to determine whether protocols for obtaining more accurate testimony from intoxicated witnesses and suspects should be developed.

With the exception of the findings from one survey of police officers (Evans, Schreiber Compo, \& Russano, 2009), we know surprisingly little about the contribution of intoxicated witnesses to criminal investigations. The present study examines the involvement of intoxicated witnesses and suspects in criminal investigations, thereby addressing these gaps in the literature. In so doing, we augment the police survey findings, which, like all findings based on self-report data, can be affected by self-report and memory biases. Field research about intoxicated witnesses is important because witness testimony is often central to the resolution of criminal cases. Police officers report that witnesses usually or almost always provide the major leads in an investigation (Kebbell \& Milne, 1998). 
Given the vital role accurate testimony plays in criminal investigations, we sought to investigate how the police manage intoxicated witnesses and suspects. Evans et al. (2009) asked their police respondents whether intoxicated witnesses are managed in the same way as sober witnesses. Nearly $44 \%$ of respondents said that the procedures are the same, while 45.5\% indicated that the procedures are different. In describing how the procedures are different, most respondents said that if witnesses are interviewed when intoxicated, they should be re-interviewed when sober. When asked whether they wait for the witness to "sober up" before conducting the interview, the majority of officers said that it "depends on the situation." Additionally, most (71.4\%) respondents stated that they do not use an instrument to measure intoxication, but instead they observe behavior and check for the odor of alcohol. We studied prosecutor case files to further examine whether witnesses under the influence are managed differently compared to sober witnesses.

A secondary aim was to study intoxicated suspects. According to a recent US survey, almost a quarter (24.2\%) of violent crimes involved an offender using alcohol or drugs (Bureau of Justice Statistics, 2008). A few studies have specifically investigated the treatment of intoxicated suspects by the legal system. In the Evans et al. (2009) survey, most police officers stated that the procedures for dealing with intoxicated suspects are the same as for sober suspects. Likewise, Sigurdsson and Gudjonnson (1994) found that interviewing procedures are more likely to continue if the interviewee is an intoxicated suspect compared to an intoxicated witness. The present study examined prosecutor case files to assess how investigators manage intoxicated suspects.

To summarize, despite extant research suggesting that intoxicated witnesses might be quite ubiquitous, we know little about whether the police manage intoxicated and sober 
witnesses differently. Toward this end, we performed an archival analysis of sober and intoxicated witnesses in felony criminal cases (rape, robbery, and assault) that were sampled from a District Attorney's case archives, which contains cases that were accepted and rejected for prosecution. Therefore, the sample consisted of cases in which a suspect had been arrested and the police forwarded the suspect's case to the District Attorney's office to consider whether the suspect should be prosecuted.

\section{Goals of the Present Study}

Our first goal was to examine whether intoxicated witnesses gave a description of the culprit to the police less often than sober witnesses. Second, we examined whether the police administered identification tests less often to intoxicated compared to sober witnesses, and whether intoxicated witnesses were less likely to select the police suspect. If the police are concerned that intoxication will affect memory for the culprit, then it follows that they should be less likely to ask intoxicated witnesses to give a description or take an identification test. Third, we sought evidence to determine whether the police interview intoxicated and sober witnesses using similar procedures. In particular, we examined whether the police tended to interview intoxicated witnesses more than once, and whether the police delayed interviewing witnesses until they are sober. Fourth, we examined the demographics of intoxicated suspects and how these suspects were treated by the legal system.

\section{Method}

\section{Case Selection}


We randomly sampled three types of felony criminal cases (rape, robbery, and assault) from the archives of a District Attorney's office that is located in a large jurisdiction in the southwestern part of the United States. In total, we coded 289 rape cases, 181 robbery cases, and 169 assault cases. Initially, we aimed to code an equal number of cases across the crime types. However, robbery and assault cases had almost twice as many witnesses and thus took longer to code compared to the rape cases. As a result, there are more rape cases in the sample.

Across the sample, $69 \%$ of the cases were prosecuted $(76 \%$ for rape, $77 \%$ for robbery, and $53 \%$ for assault), whereas no charges were filed for the remaining cases. We selected these serious violent crimes because they were likely to have witnesses. Statutory rape and child molestation cases were not included. The arrest rates for rapes (45\%), robberies $(34 \%)$, and assaults $(72 \%)$ for this city during the study period were comparable to national arrest rates $(51 \%, 25 \%$, and $56 \%$, respectively; U. S. Department of Justice, Federal Bureau of Investigation, 1996).

A total of 1307 ( $53 \%$ female) witnesses and 786 (3\% female) suspects were represented in this sample. Witnesses were aged between 4 and $86(M=29.30, S D=13.00)$ years. One hundred and eighty-nine witnesses were aged 17 years or below. The ethnic breakdown of the witnesses was as follows: 50\% White, 25\% Hispanic, 18\% African American, $6 \%$ Asian, and $1 \%$ were reported as belonging to the "other" category.

\section{Materials}

Our data were coded from the 3 types of forms used by police in this jurisdiction. First, the Crime/Incident report provided a synopsis of the crime and recorded individual 
witness statements. This report contained standard fields in which to enter detailed information about each of the witnesses, including whether the witness was under the influence of alcohol or drugs. Similar to the police surveyed by Evans et al. (2009), the police in this jurisdiction determined intoxication based on smelling the substance, witnessing the intoxicant being consumed and/or detecting physical symptoms of use, such as bloodshot eyes, and/or whether the witness admitted to being under the influence. At least in the United States, witnesses and victims of crimes are generally not breathalyzed as a matter of routine. Additionally, if an identification procedure was conducted at the scene of the crime, this detail was usually indicated on the Crime/Incident Report. The second form was the Arrest Report, which described how the suspect was taken into custody. The form also contained information about whether the perpetrator was under the influence of alcohol and/or drugs and how this was determined (police observation, suspect admittance, witness report, alcohol and/or drug test). The third type of form, the Case Follow-up Report, provided information about whether the witness was interviewed on a date later than the crime, and details about any witness identification test. We also obtained the preliminary trial transcript for each case to determine whether a given witness had testified.

\section{Measures}

At the case level, we analyzed crime type (rape, robbery, or assault). At the witness level, we coded demographic information, including the witnesses' relationship to the suspect; whether or not the witness was intoxicated (see below), whether the witness witnessed violence (coded as 'yes' if the witnesses reported the culprit displayed a weapon or made threats with a concealed weapon, or if the witness engaged or saw someone else engaged in a physical confrontation with the culprit; otherwise, coded as 'no'); whether the 
witnesses gave multiple descriptions; the time delay between the crime and their description (same day, next day, more than 30 days later) and details about the ID procedure-including whether an ID attempt was made, what type of procedure was used and the witnesses' response to the ID test (ID suspect, ID foil, ID more than one person, not ID anyone, other). For suspects, we coded demographic information such as age, ethnicity, gender and crime type, and crucially, whether the suspects were intoxicated, of which substances they were under the influence, and how substance use was determined. Other variables included whether the suspect admitted to the crime, whether they were prosecuted, when they were arrested, and whether they gave a statement.

Research assistants who completed the coding received comprehensive training, including detailed written and verbal instructions, and a number of practice cases. We examined coder reliability by having more than one research assistant code a random subset of the case files. Agreement between coders was extremely high (e.g., 100\% for crime type, $100 \%$ for witness identification procedure type; $97 \%$ for total number of physical descriptors), indicating highly reliable coding. Coders resolved disagreements before the data were entered for analysis.

\section{Results}

\section{Witness Intoxication Findings}

Characteristics of intoxicated witnesses. In addressing the main research questions regarding the involvement of intoxicated witnesses in crime investigations, we took into account both case and witness factors in the analyses. Univariate statistics for these factors 
appear in this section, and multivariate inferential statistical test results are presented in subsequent sections.

One hundred and thirty cases involved at least one witness who was reportedly under the influence of alcohol. The majority of these cases were rape cases (71\%), followed by assault (18\%) and then robbery $(11 \%)$ cases. The prevalence of intoxicated witnesses did not vary depending on whether or not charges were filed against the defendant (13\% versus $17 \%$, respectively).

Of the 1307 witnesses across the cases in the sample, 170 were reportedly under the influence of alcohol and/or drugs when they witnessed the crime. For the majority (88\%) of these witnesses, the police established that the witness was under the influence because the witness admitted to drinking alcohol and/or taking drugs. In the remaining cases, police either breathalyzed the witness (9\%) or observed him or her consuming alcohol and/or drugs (3\%).

The majority of witnesses under the influence (73\%) had consumed only alcohol. Some witnesses had taken multiple drugs (11\%), with the most common combination being alcohol and marijuana (4\%). Other types of drugs consumed by witnesses under the influence included marijuana (5\%), methamphetamine (3\%), cocaine (3\%), crack (2\%), the recreational use of prescription drugs, such as Xanax (2\%), and other (1\%) drugs.

As can be seen in Table 1, compared to sober witnesses, intoxicated witnesses were significantly more likely to have been previously acquainted with the culprit, to have experienced violence during the crime, and to have been given an opportunity to describe the culprit. Intoxicated and sober witness who provided a description of the culprit to the 
police most often did so on the same day as the crime ( $72 \%$ versus $79 \%$, respectively), followed by the day after the crime ( $22 \%$ versus $15 \%)$.

Intoxicated and sober witnesses were equally likely to have been given the opportunity to identify the culprit. Table 2 shows the distribution of identification test types by witness intoxication. Witnesses were most likely to see a live showup. With respect to identification outcomes, under the influence witnesses positively identified the suspect $91 \%$ of the time and sober witnesses positively identified the suspect $87 \%$ of the time across all identification tests.

\section{Are witnesses under the influence less likely to give descriptions of the culprit} compared to sober witnesses? Our next set of analyses focused on whether intoxicated witnesses were less likely to provide the police with a description of the suspect compared to their sober counterparts, after controlling for other case factors. We adopted a multilevel modeling approach here to account for possible dependence of the outcome variable on witnesses having viewed the same suspect (see Gelman \& Hill, 2007). Thus, data were hierarchically structured, with witnesses nested within suspect.

We ran the analysis using crime type (rape, assault, robbery), witness intoxication (coded 1 for "yes", and 0 for "no"), whether the witness knew the culprit (coded 1 for "yes", and 0 for "no"), and whether the witness experienced any violence (coded 1 for "yes", and 0 for "no") as predictors. We included the latter variable in the analysis because it was thought to index opportunity to view the culprit, with witnesses experiencing violence potentially having a better view compared to their counterparts (see Yuille \& Cutshall, 1986). The outcome variable in the analysis was whether or not the witness provided a 
description of the culprit, where providing a description was coded as 1 , and not providing a description was coded as 0 . Table 3 shows the results of the analysis.

The overall model was statistically significant, Wald $\chi^{2}(5)=91.01, p<.001$. As shown in Table 3, witnesses were significantly more likely to provide a description of the culprit to the police if they experienced violence, and less likely to provide description if they knew the culprit, and if the crime was assault rather than robbery. Most important for the purposes of the present study, witnesses who were under the influence of alcohol and/or drugs were not less likely to provide descriptions compared to sober witnesses. Being the sole witness versus being one of multiple witnesses did not influence whether a witness provided a description to the police. Interaction terms for the predictors were added to the model, but model fit was not improved, nor were any of the interactions significant.

Are witnesses under the influence less likely to take identification tests compared to sober witnesses? Another multilevel logistic regression analysis was performed to test this question. Using the same predictors, we examined whether or not the witness was asked to take an identification test.

The model produced a significant fit to the data, Wald $\chi^{2}(5)=63.45, p<.001$. Witnesses were significantly more likely to have an identification opportunity if they experienced violence, and less likely to have an identification opportunity if they knew the culprit, or if the crime was assault or rape rather than robbery (see Table 3). Witness intoxication did not affect the likelihood that witnesses were given identification tests. Interaction terms were entered into the model, but the model fit was not improved, nor were any of the interactions statistically significant. 


\section{Suspect Intoxication Findings}

Of the 786 suspects in the sample, 225 (28.63\%) were under the influence of alcohol or drugs during the alleged commission of the crime. Of these suspects, 115 were allegedly involved in rapes, 64 in robberies and 46 in assaults. For 223 suspects, the police reports contained information about which substance they had reportedly been using. The majority ( $n=140,62.8 \%)$ were under the influence of alcohol alone, and 35 suspects (15.70\%) were under the influence of multiple drugs. Other drugs consumed included marijuana (6\%), methamphetamine (6\%), cocaine (5\%), crack cocaine (2\%), and heroin ( $2 \%)$.

Half the suspects (50\%) admitted to the police that they were under the influence of alcohol and/or drugs during the alleged crime. Few suspects were drug tested (12\%). As for the remaining suspects, in $20 \%$ of cases a witness reported that the suspect had been using alcohol and/or drugs, and in $8 \%$ of cases, a law enforcement officer observed the suspect using alcohol and/or drugs.

Suspects who were under the influence were not more likely than sober suspects to admit to the crime (47\% versus 54\%). A total of 168 of the 225 suspects who were reportedly under the influence during the alleged commission of the crime gave a statement to the police. We were unable to determine from police records whether the suspects were under the influence while they gave their statement. However, of the 178 intoxicated suspects whose arrest and crime date is known, the majority $(n=101)$ were arrested on the 
same day as the crime was allegedly committed, opening the door to the possibility that suspects were still under the influence when questioned by the police.

\section{Discussion}

This study gathered information from a District Attorney's archives about intoxicated witnesses and suspects who were involved in serious violent crimes. Thirteen percent of witnesses in the sample were under the influence of alcohol and/or other drugs. In keeping with the police survey conducted by Evans et al. (2009), alcohol was the most common substance used. Witnesses also used other types of drugs, including illegal and prescription drugs. The results further indicated that the police most often became aware that the witness had been under the influence during the crime because the witness or suspect admitted this information to them.

Under the influence and sober witnesses were found to play similar roles in criminal case processing. Both intoxicated and sober witnesses were usually questioned on the same day as the crime, suggesting that the police were not routinely delaying their interviews with intoxicated witnesses. Furthermore, intoxicated and sober witnesses were equally likely to give a description of the culprit and to be administered an identification test. Lastly, there was no difference across sober and intoxicated witnesses with regard to the type of identification procedure conducted, or the likelihood that the witness made a positive identification of the suspect.

Finally, we also had the opportunity to investigate the prevalence of intoxicated suspects. In total, $28 \%$ of the suspects were allegedly under the influence, which is a figure 
that is in keeping with a national survey (Bureau of Justice Statistics, 2008). Typically the suspects who were under the influence were thought to have consumed alcohol. As was the case with intoxicated witnesses, the vast majority of suspects admitted to the police that they were under the influence, with only a minority being drug tested or breathalyzed. Intoxicated suspects were not more likely than sober suspects to admit to the crime for which they were being accused, and they were also no more likely to be convicted.

In the main, our results indicate that intoxicated witnesses and suspects are significantly involved in the criminal justice process, and that the police treat the sober and intoxicated people similarly when gathering information from them. Police probably cannot altogether avoid gathering and relying on testimony that is given by intoxicated people. An intoxicated witness, for example, may be the first person to report the crime and the police might have to question that witness to develop the initial leads in a case. What is more, in some crimes such as rape, an intoxicated victim is often the only witness. As such, research that can guide the development of interview protocols to assist the police and first responders in ascertaining accurate information would make an important contribution to criminal case processing. In the discussion that follows, potential areas for further research are identified.

First, future research should further investigate the effects of repeated and delayed interviewing on the accuracy of testimony rendered by witnesses who were under the influence during the crime. Many police believe intoxicated witnesses should be interviewed more than once (Evans et al., 2009). In the present study, we found that most witnesses, both sober and intoxicated, were interviewed on the same day as the crime. On the one hand, interviewing witnesses soon after the crime has the mnemonic benefit of slowing 
down the rate of forgetting (Odinot \& Wolters, 2006). Additionally, previous research has found that interviewing a witness multiple times helps to preserve the accuracy of memory across the retention interval in both sober (Ebbesen \& Rienick, 1998) and intoxicated (Yuille \& Tollestrup, 1990) participants. On the other hand, delayed interviewing can introduce variables that negatively impact memory. For instance, increasing the retention interval between the crime and the police interview increases the probability that a witness may be exposed to misleading post-event information (see Read \& Connolly, 2007). Clearly further research on delayed and repeated interviewing with intoxicated witnesses is warranted, especially given the fact that already in some jurisdictions the police re-interview intoxicated witnesses (Evans et al., 2009).

Second, consideration should be given to the fact that intoxicated witnesses and suspects will often be from sexual assault cases. The majority of intoxicated victims and suspects in our sample were from rape cases, a finding that is in keeping with police survey data (Evans et al., 2009) and other research showing that alcohol is ubiquitous in sexual assault (e.g., Testa, 2002). Accordingly, the development of special interview procedures for intoxicated witnesses will have a larger impact on the investigation of sexual assault compared to other types of crimes. To illustrate, if the police delay the interview until the suspect is sober, an intoxicated suspect will be afforded more time to prepare than a sober suspect. As a result, delayed interviewing could impact the prosecution rate for rape cases.

A third area that would be fruitful for future work is the likelihood that an intoxicated suspect will admit to a particular crime. Intoxicated suspects possible are more likely to confess to a crime, regardless of their true guilt or innocence. For example, drawing on alcohol myopia theory, Evans et al. (2009) argue that intoxicated suspects may be 
particularly likely to attend to the salient cues of an interrogation, such as the benefits rather than long-term risks of giving a confession, leading them to confess more often than sober suspects.

\section{Limitations and Summary}

It is important to raise a number of study limitations. First, our sample comprises cases that were referred by the police to a District Attorney's office for prosecution. Our data do not address the role that intoxicated witnesses and suspects play in criminal investigations in which no arrest was made. When there is no arrest made, witnesses might be relatively more intoxicated on average and thereby suffer greater memory impairment. Intoxicated eyewitnesses may be less likely to give a description in cases in which no arrest has been made. Additionally, if intoxicated eyewitnesses provide poor quality information the police may be less likely to arrest the suspect and forward the case for prosecution. Second, we could not ascertain the level at which witnesses were intoxicated during the crime or during the police interview because the police do not usually breathalyze witnesses. Third, we cannot definitively determine whether the suspect/defendant was in fact the guilty culprit. Other archival studies (e.g. Mann, Vrij, \& Bull, 2002; Berman \& Davey, 2001; Horry, Memon, Wright, \& Milne, 2011) have similarly not been able to establish the guilt of the suspect. Hence, we cannot ultimately determine the accuracy of witness identifications in archival studies as we could in a laboratory study. Fourth, some witnesses and suspects were under the influence of drugs other than alcohol, or multiple drugs. Our sample did not include enough such witnesses to examine the role that other drugs play in witness and suspect testimony. Fifth, the sample of cases was drawn from a limited number 
of crime types. Additional research on other crime types where alcohol is a significant factor would certainly be beneficial. Sixth, the rates at which sober and intoxicated witnesses identified the suspect cannot be extrapolated beyond the parameters of the present study (i.e., a case population in which an arrest had been made). Cases with an arrest may be more likely to involve positive witness identification evidence than cases without an arrest (see also Flowe, et al., 2011). Finally, we do not know whether the police are differentially likely to follow-up on information provided by intoxicated compared to sober witnesses. Police may not be keen to use information provided by an intoxicated eyewitness in their investigation. How the police prioritize interviewing witnesses and follow-up on the information they provide are interesting topics for further research.

In sum, the present study found that intoxicated witnesses and suspects are involved in criminal investigations. Witnesses who are under the influence are just as likely as sober witnesses to provide testimony to the police and are often administered identification tests. Additionally, the case sample suggests that the police encounter a sizeable number of intoxicated suspects. The results of this archival study indicate that additional research is clearly warranted on the topic of intoxicated witnesses and suspects. Best practices for interviewing intoxicated witnesses and suspects need to be identified. 


\section{References}

Berman, B. W. \& Davey, S. L. (2001). Witness identification in actual criminal cases: An archival analysis. Law and Human Behavior, 25, $475-491$. doi:10.1023/A:1012840831846

Bisby, J. A., Leitz, J. R., Morgan, C. J. A., \& Curran, H. V. (2010). Decreases in recollective experience following acute alcohol: A dose-response study. Psychopharmacology, 208, 67-74. doi:10.1007/s00213-009-1709-y

Brown, J., Brignell, C. M., Dhiman, S. K., Curran, H. V., \& Kamboj, S. K. (2010). Acute effects of alcohol on memory: Impact of emotional context and serial position. Neurobiology of Learning and Memory, 93, 428-434. doi:10.1016/j.nIm.2009.12.010

Bureau of Justice Statistics (2008). Criminal Victimization in the United States, 2008. Retrieved from http://bjs.ojp.usdoj.gov/index.cfm?ty=pbdetail\&iid=1975.

Clifasefi, S. L., Takarangi, M. K., \& Bergman, J. S. (2006). Blind drunk: The effects of alcohol on inattentional blindness. Applied Cognitive Psychology, 20, 697-704. doi:10.1002/acp.1222

Dysart, J. E., Lindsay, R. C. L., MacDonald, T. K. \& Wicke, C. (2002). The intoxicated witness: effects of alcohol on identification accuracy from showups. Journal of Applied Psychology, 87, 170-175. doi: 10.1037/0021-9010.87.1.170

Ebbesen, E. B., \& Rienick, C. B. (1998). Retention interval and witness memory for events and personal identifying attributes. Journal of Applied Psychology, 83, 745-762. doi:10.1037/0021-9010.83.5.745 
Evans, J. R., Schreiber Compo, N. \& Russano, M. B. (2009). Intoxicated witnesses and suspects: Procedures and prevalence according to law enforcement. Psychology, Public Policy and Law, 15, 194-221. doi: 10.1037/a0016837

Flowe, H. D., Mehta, A., \& Ebbesen, E. B. (2011). The role of witness identification evidence in felony case processing. Psychology, Public Policy and Law, 17, 140-159. doi: $10.1037 / \mathrm{a} 0021311$

Gelman, A., \& Hill, J. (2007). Data Analysis Using Regression and Multilevel/Hierarchical Models. Cambridge University Press.

Hashtroudi, S., Parker, E. S., DeLisi, L. E., Wyatt, R. J. \& Mutter, S. A. (1984). Intact retention in acute alcohol amnesia. Journal of Experimental Psychology: Learning, Memory and Cognition, 10, 156-163. doi: 10.1037/0278-7393.10.1.156

Horry, R., Memon, A., Wright, D. B. \& Milne, R. (2011). Predictors of witness identification decisions from video lineups in England: A field study. Law and Human Behavior. doi: $10.1007 /$ s10979-011-9279-z

Kebbel, M. R. \& Milne, R. (1998). Police officers' perceptions of witness performance in forensic investigations. The Journal of Social Psychology, 138, 323-330. doi: $10.1080 / 00224549809600384$

Mann, S., Vrij. A. \& Bull, R. (2002). Suspects, Lies and Videotape: An analysis of authentic high-stake liars. Law and Human Behavior, 26, 365 - 376. doi: 10.1023/A:1015332606792

Maylor, E. A., \& Rabbitt, P. M. (1993). Alcohol, reaction time and memory: A meta-analysis. British Journal of Psychology, 84, 301-317. doi: 10.1111/j.2044-8295.1993.tb02485.x 
Odinot, G., \& Wolters, G. (2006). Repeated Recall, Retention Interval and the AccuracyConfidence Relation in Witness Memory. Applied Cognitive Psychology, 20, 973-985. doi:10.1002/acp.1263

Ray, S., \& Bates, M. E. (2006). Acute alcohol effects on repetition priming and word recognition memory with equivalent memory cues. Brain and Cognition, 60, 118127. doi:org/10.1016/j.bandc.2005.07.009

Read, J. D., \& Connolly, D. A. (2007). The effects of delay on long-term memory for witnessed events. In M. P. Toglia, J. D. Read, D. F. Ross, \& R. C. L. Lindsay (Eds.), Handbook of witness psychology: Volume I: Memory for events (pp. 117-155). Mahwah, NJ: Erlbaum Associates Inc.

Read, J. D., Yuille, J. C., \& Tollestrup, P. (1992). Recollections of a robbery. Effects of arousal and alcohol upon recall and person identification. Law and Human Behavior, 16, 425-446. doi:10.1007/BF02352268

Roizen, J. (1993). Issues in the epidemiology of alcohol and violence. In S. E. Martin (Ed.), Alcohol and interpersonal violence: Fostering multidisciplinary perspectives. ( $\mathrm{NIH}$ Publication No. 93-3496, Research Monograph 24). Rockville, MD: U.S. Department of Health and Human Services.

Schreiber Compo, N., Evans, J. R., Carol, R. N., Villalba, D., Ham, L. S., Garcia, T., \& Rose, S. (2011). Intoxicated Witnesses: Better than Their Reputation? Law and Human Behavior. doi: 10.1007/s10979-011-9273-5

Sigurdsson, J. F. \& Gudjonsson, G. H. (1994). Alcohol and drug intoxication during police interrogation and the reasons why suspects confess to the police. Addiction, 89, 985997. doi: 10.1111/j.1360-0443.1994.tb03358.x 
Soraci, S. A., Carlin, M. T., Read, J. D., Pogoda, T. K., Wakeford, Y., Cavanagh, S., \& Shin, L. (2007). Psychological impairment, witness testimony, and false memories: Individual differences. In M. P. Toglia, J. D. Read, D. F. Ross, \& R. C. L. Lindsay (Eds.), The handbook of witness psychology: Volumne 1. Memory for events (pp 261-297). Mahwah, NJ: Erlbaum.

Steele, C. M., \& Josephs, R. (1990). Alcohol myopia: Its prized and dangerous effects. American Psychologist, 45, 921-933. doi: 10.1037/0003-066X.45.8.921

Testa, M. (2002). The impact of men's alcohol consumption on perpetration of sexual aggression. Clinical Psychology Review, 22, 1239-1263. doi:10.1016/S02727358(02)00204-0

U. S. Department of Justice, Federal Bureau of Investigation (1996). Crime in the United States: Uniform Crime Reports, 1995. Washington, D.C.: U.S. Department of Justice. Valentine, T., Fauzia, C., Fantham, V. \& Davis, J. P. (2012). Accuracy and confidence of identification by intoxicated witnesses. Paper presented at European Association of Psychology and Law Conference, Nicosia, Cyprus, April 2012.

van Oorsouw, K., \& Merckelbach, H. (2012). The effects of alcohol on crime-related memories: A field study. Applied Cognitive Psychology, 26, 82-90. doi: 10.1002/acp.1799

Yuille, J. C., \& Cutshall, J. L. (1986). A case study of witness memory of a crime. Journal of Applied Psychology, 71(2), 291-301. doi: 10.1037/0021-9010.71.2.291

Yuille, J. C. \& Tollestrup, P. A. (1990). Some effects of alcohol on witness memory. Journal of Applied Psychology, 75, 268-273. doi: 10.1037/0021-9010.75.3.268 
Table 1

Relationship between witness intoxication and other case factors

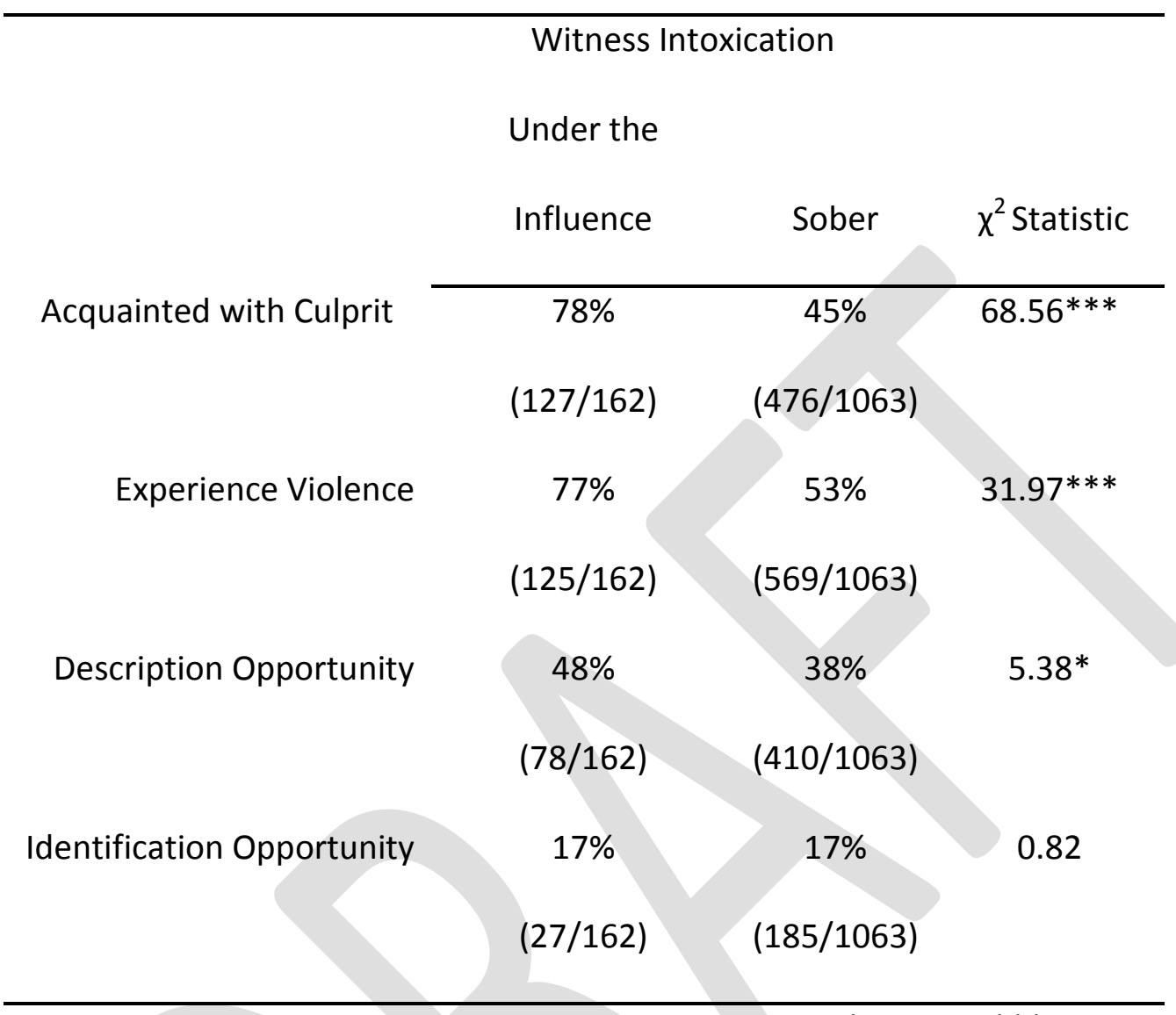

Table Notes: Frequency data are given in parentheses; ${ }^{*} p<0.05$, $p<.001$ 
Table 2

Distribution of Witness Identification Tests for Under the Influence and Sober Witnesses

\begin{tabular}{|c|c|c|c|c|}
\hline & \multicolumn{2}{|c|}{ Under the Influence } & \multicolumn{2}{|c|}{ Sober } \\
\hline & $n$ & $\%$ & $n$ & $\%$ \\
\hline Live lineup & 0 & 0 & 7 & 2 \\
\hline Live showup & 21 & 55 & 162 & 52 \\
\hline Simultaneous photo & 15 & 39 & 126 & 41 \\
\hline lineup & & & & \\
\hline Photo showup & 0 & 0 & 4 & 1 \\
\hline Other & 2 & 6 & 11 & 4 \\
\hline Total & 38 & 100 & 310 & 100 \\
\hline
\end{tabular}


Table 3

Beta Coefficients (z statistic) for Multilevel Models of Description Opportunity and ID Opportunity

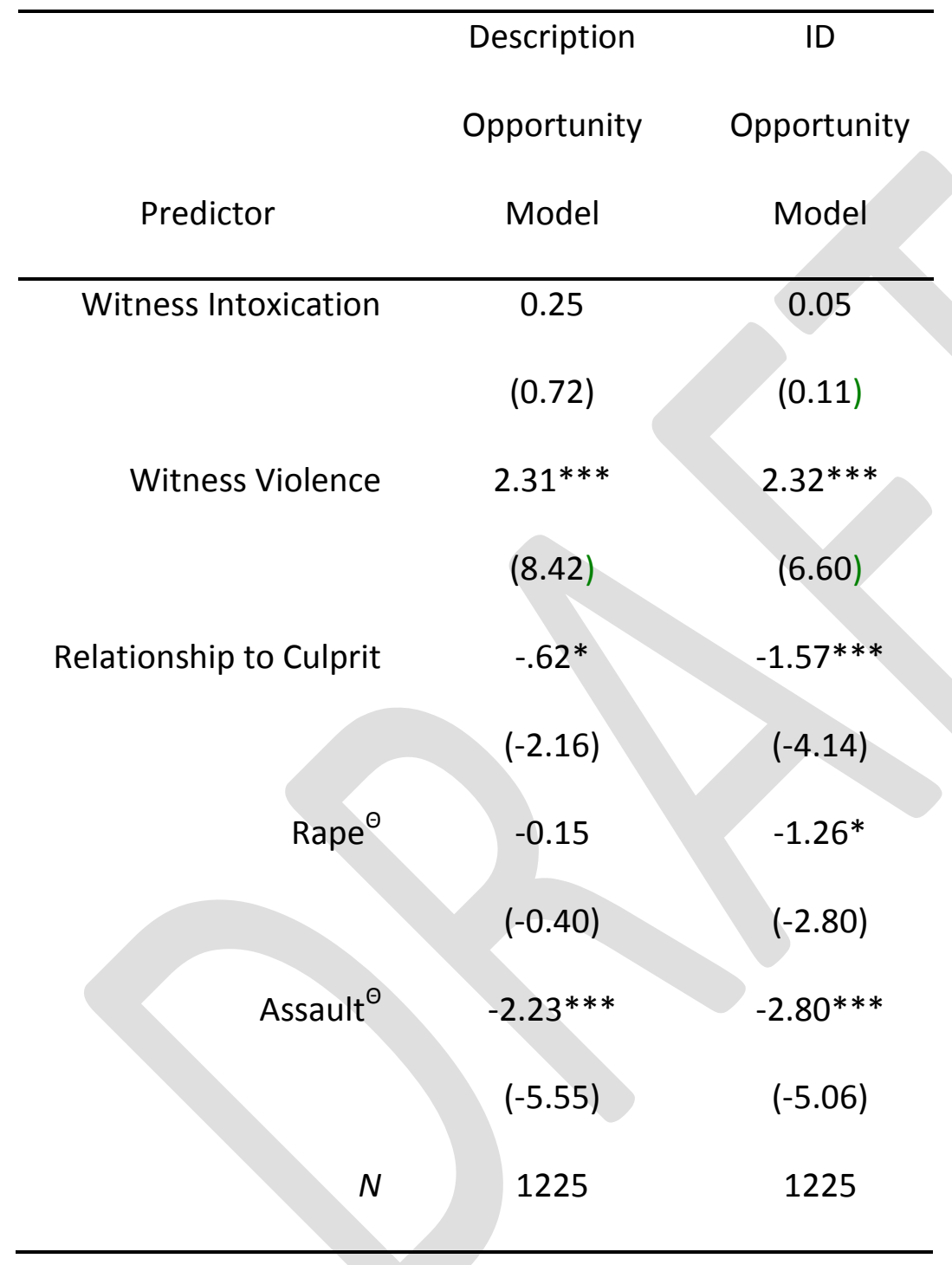

